\title{
La Biblioteca Central del Ministerio de Hacienda
}

\author{
MARISA MARTÍNEZ SORO \\ Ministerio de Hacienda
}

\begin{abstract}
La Biblioteca Central del Ministerio de Hacienda es una biblioteca especializada en Hacienda Pública, Economía, Derecho e historia económica y una de las principales bibliotecas españolas de temas fiscales.

Creada en 1850, en la actualidad ocupa uno de los patios del edificio de la Real Casa de Aduana, actual sede del Ministerio de Hacienda desde 1845, en la calle de Alcalá de Madrid.

La Biblioteca Central está adscrita a la Subdirección General de Información, Documentación y Publicaciones, dependiente de la Secretaría General Técnica del Departamento (Subsecretaría de Hacienda)

Como biblioteca de titularidad estatal de la Administración General del Estado, su principal función es servir de apoyo al trabajo del personal del Ministerio de Hacienda, si bien está abierta a los investigadores con cita previa.
\end{abstract}

Bibliotecas especializadas; bibliotecas estatales; atención de usuarios

La Biblioteca Central del Ministerio de Hacienda es una unidad administrativa adscrita a la Subdirección General de Información, Documentación y Publicaciones, dependiente de la Secretaría General Técnica del Departamento, órgano de la Subsecretaría de Hacienda.

\section{Historia}

La historia de la Biblioteca Central de Hacienda ha ido de la mano del Archivo General Central de Hacienda (actual Archivo Central de Hacienda) hasta fechas recientes, tal y como explica Agustín Torreblanca (2002, p. 13-22). ${ }^{1}$

Ambas unidades fueron creadas en 1850. El Decreto de 18 de febrero de 1871, por el que se aprueba el Reglamento para el régimen y tramitación de los negocios en el Ministerio de Hacienda, estableció un servicio de Archivo y Biblioteca bajo dependencia directa del Subsecretario, confiando su servicio a un empleado del Cuerpo de Archiveros-Bibliotecarios. Desde entonces, ambos centros se han mantenido adscritos a la Subsecretaría de Hacienda. Con posterioridad, la Ley de 30 de junio de 1894, dispuso que el archivo y la biblioteca del Ministerio de Hacienda (como el resto de archivos, bibliotecas y museos dependientes de la Presidencia del Consejo de

1 Torreblanca López, A. (2002) Tesoros del Archivo del Ministerio de Hacienda. Madrid: Ministerio de Hacienda, Centro de Publicaciones.

Bajo el principio de que el acceso abierto a los resultados de investigación acelera el avance del conocimiento, todos los contenidos de la edición electrónica de CLIP se distribuyen bajo una licencia de uso y distribución Creative Commons Reconocimiento-NoComercialCompartirlgual 3.0 España (CC BY-NC-SA 3.0 ES). 
Ministro o de otros ministerios) estuvieran a cargo de empleados del Cuerpo Facultativo de Archiveros, Bibliotecarios y Anticuarios. Esa unión, debido a la carencia de personal suficiente, se mantuvo hasta el 1906. Volvieron a unirse en 1917 (Real Orden del Ministerio de Hacienda, de 15 de septiembre de 1917, distribuyendo los servicios de la Subsecretaría), constituyendo una sección dependiente del Subsecretario. En enero de 1946 se establecieron unas normas provisionales para el régimen del archivo y de la biblioteca, que dividieron el archivo en dos secciones, pasando a ser la biblioteca una tercera sección. Al frente de cada una de ellas se situó a un archiverobibliotecario del Estado.

Su encuadramiento orgánico solo ha variado a lo largo del tiempo por debajo del nivel de la Subsecretaría. Hasta 1996, la biblioteca y el archivo han dependido directamente de la Oficialía Mayor. A partir de ese año, y hasta la fecha, dependen de la Secretaría General Técnica, adscritos al Centro de Publicaciones y Documentación primero y, desde el año 2000, a la Subdirección General de Información Documentación y Publicaciones. En 1999 se produjo la separación de ambos servicios.

La actual biblioteca, ubicada en la planta baja del número 9 de la madrileña calle de Alcalá, fue inaugurada en 2002 en el espacio ocupado anteriormente por la Caja General de Depósitos, que en el año 2000 había sido trasladada al Paseo del Prado. Hasta esa fecha, ocupaba las dependencias del actual servicio médico del Departamento. La biblioteca está instalada en uno de los patios laterales del edificio originario, la Real Casa de Aduana, diseñada por Francisco Sabatini y, desde 1845, sede del Ministerio de Hacienda. La estructura de la biblioteca se adapta a una gran cúpula que cierra el patio, que sustituyó al anterior cerramiento acristalado. La cúpula, considerada un hito de la arquitectura para su tiempo, fue construida en 1963 por el arquitecto Damián Galmés de Fuentes en forjado de hormigón y vidrio translúcido con un espesor de $7 \mathrm{~cm}$. La construcción de la biblioteca respetó la estructura original del patio diseñado por Sabatini. Actualmente la biblioteca es la puerta de entrada a la exposición permanente Crónica gráfica del Ministerio de Hacienda, ubicada en los sótanos del edificio.

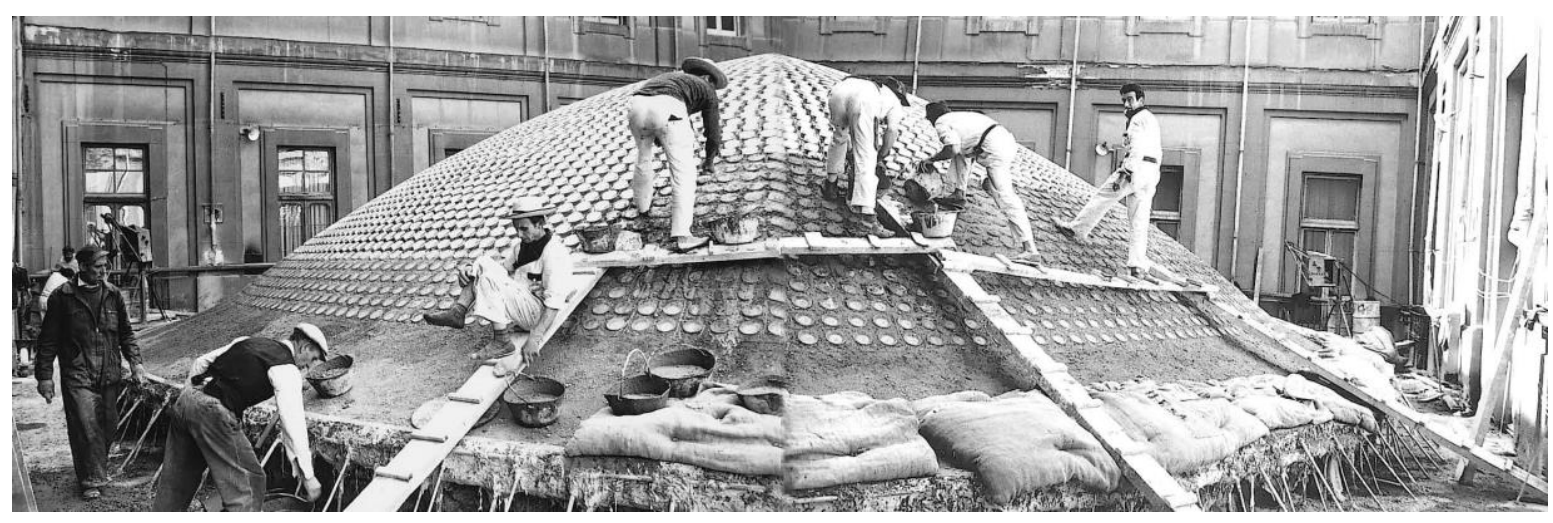

Figura1: Construcción de la cúpula de la sala de lectura 


\section{Servicios de la Biblioteca Central de Hacienda}

La Biblioteca Central de Hacienda está especializada en Hacienda Púbica, Economía, Derecho e historia económica y actualmente puede ser considerada una de las principales bibliotecas españolas sobre temas fiscales. Su misión principal es servir de apoyo al personal del Ministerio, si bien se permite el acceso con cita previa de los investigadores.

La sala de lectura -a disposición también de los usuarios del Archivo Central- dispone de una amplia colección de referencia especializada de libre acceso. Una zona de la sala está reservada para la consulta, también de libre acceso, de los números de las revistas especializadas recibidos en el año en curso en la biblioteca. Con cobertura wifi en todos sus espacios, la sala está dotada con veintitrés puestos de consulta, cuatro ordenadores con acceso público a Internet y acceso directo al catálogo y a los recursos electrónicos de la biblioteca a través del portal de la Biblioteca en la intranet corporativa. Hay también una impresora y una copiadora monedero para uso de los usuarios externos. (Los usuarios internos pueden utilizar el servicio de reprografía de forma gratuita).

Como se ha señalado anteriormente, la función principal de la Biblioteca Central, como la de la gran mayoría de bibliotecas de la Administración General del Estado, es servir de apoyo al trabajo del personal del Departamento, sea cual sea la sede ministerial en la que desempeñen sus funciones, cubriendo sus necesidades de información: atención de consultas bibliográficas y desideratas, reproducción de documentos, lectura en sala y préstamo domiciliario.

En la actualidad, la atención al usuario interno se realiza mayoritariamente a través de correo electrónico, con la excepción del servicio de préstamo domiciliario, pudiendo, no obstante, renovar las publicaciones en préstamo a través de correo electrónico. La consecuencia inmediata es la reducción progresiva de la atención presencial en sala. A ello ha contribuido también la existencia de un portal específico de la biblioteca en la intranet corporativa.

Por resolución de la Subsecretaría, y con objeto de centralizar y racionalizar los gastos, la contratación de recursos de información del Departamento está centralizada en la Biblioteca Central y el acceso a todos los recursos electrónicos de información se realiza a través del portal de la biblioteca en la intranet.

Los principales recursos de información a disposición de los usuarios internos a través del portal de la Biblioteca Central son:

- OPAC de la biblioteca;

- la plataforma de préstamo de libros electrónicos (Biblioteca digital MINHAC), accesible también desde la extranet, para la descarga y/o préstamo de libros-e especializados, en formato PDF y EPUB;

- bases de datos especializadas, por suscripción y de acceso gratuito;

- revistas electrónicas especializadas, por suscripción y de acceso gratuito;

- prensa digital nacional y extranjera, por suscripción y de acceso gratuito;

- repositorio de cursos generalistas y especializados, de acceso libre y gratuito (MOOC);

- enlaces a los principales organismos nacionales e internacionales, bancos, bibliotecas, servicios de estudios y fundaciones, etc., de temas relacionados con los intereses del Ministerio de Hacienda, incluidos todos aquellos relacionados con la administración electrónica;

- repositorio de plataformas digitales, públicas y privadas, que permiten la descarga legal de libros gratuitos. 
A fecha de 31 de marzo de 2021, el número de recursos electrónicos disponibles para consulta a través del portal de la biblioteca está en torno a los 2.500 recursos.

La biblioteca ofrece un servicio de préstamo interbibliotecario, en especial con otras bibliotecas de la Administración General del Estado, así como con bibliotecas de su misma especialización. Por lo que se refiere a los usuarios externos, la asistencia de investigadores también se ha visto reducida en los últimos tiempos. Ello se ha debido, en gran parte, a la digitalización llevada a cabo en la biblioteca desde el año 2000, que ha permitido la consulta y descarga del texto completo de las publicaciones más demandadas a través del OPAC del catálogo, sin necesidad de desplazarse a la biblioteca.

\section{Biblioteca virtual y digitalización}

La automatización del catálogo de la Biblioteca Central de Hacienda se llevó a cabo en el año 2002 con la adquisición del software de gestión bibliotecaria Basis Techlib, que permitía, además, la integración y descarga de imágenes a través del OPAC.

Se digitalizaron los índices y las cubiertas de las monografías existentes en el catálogo hasta la fecha, así como el texto completo de alrededor de mil quinientos textos clásicos de Economía y Hacienda Pública, libres de derechos de autor. Con posterioridad, se abordaron otros proyectos de digitalización. En 2007, se digitalizaron las cubiertas y los índices de los números editados en los seis últimos años de seiscientos títulos de revistas especializadas. En 2008, se emprendió la digitalización de algo más de mil folletos de obras clásicas de Economía y Hacienda Pública, libres de derechos de autor. Actualmente, la descripción bibliográfica de todas las monografías y publicaciones periódicas que ingresan en la biblioteca se enriquece con las cubiertas e índices de los mismos. Por último, desde 2004, el catálogo incluye también el texto completo de las obras publicadas por la Subdirección General de Información, Documentación y Publicaciones, a la que pertenece la Biblioteca Central.

A fecha de 31 de marzo de 2021, las cifras de digitalización son las siguientes:

- registros bibliográficos con cubierta asociada: 45.120;

- registros bibliográficos con índice asociado: 35.110;

- registros de ejemplar con índice asociado (monografías multivolumen y números de revistas): 20.970;

- monografías y folletos a texto completo: 2.803;

- números de publicaciones periódicas a texto completo: 2.840 .

EI OPAC de Basis Techlib de la Biblioteca Central incluía dos subcolecciones independientes, Fondo Histórico Virtual (documentos históricos de la Biblioteca Central y del Archivo Central) y Fototeca, además de un paseo virtual y unas guías locutadas. Sin embargo, la versión obsoleta de Techlib que utilizaba la biblioteca, así como su incompatibilidad con los principales estándares bibliotecarios, llevó a la decisión de cambiar de sistema de gestión en el año 2009. Se hizo un estudio previo de los programas de bibliotecas disponibles en el mercado, que concluyeron con la adquisición, en 2011, del software de gestión Millennium, de la empresa Innovative, que entró en funcionamiento en 2012. Lamentablemente, el software Millennium no permitió conservar la estructura de dichas subcolecciones, pero se mantuvo el acceso a las imágenes a través del enlace incluido en los registros bibliográficos y/o de ejemplar. 
La colección de la Biblioteca Central de Hacienda en cifras

A fecha de 31 de marzo de 2021, los fondos principales de la biblioteca son los siguientes:

- monografías modernas (publicadas desde 1901 inclusive): 63.636 ejemplares;

- monografías antiguas (publicadas antes de 1900 inclusive): 5.803 ejemplares. El fondo antiguo de la biblioteca está formado mayoritariamente por libros del siglo XVIII, y, sobre todo, del siglo XIX, aunque conserva 17 ejemplares del siglo XVI y 106 ejemplares del siglo $\mathrm{XVII}$;

- manuscritos: 119 (siglos XVIII- XX);

- publicaciones periódicas: 3.300 títulos:

- $\quad 2.881$ títulos de revistas cerradas;

- 89 títulos de revistas en curso de recepción;

○ 330 revisitas electrónicas.

- fotografías: cerca de 1.400 fotografías sobre el edificio del Ministerio de Hacienda y sus tesoros artísticos, la historia y cambios del propio Ministerio a lo largo del tiempo y el entorno urbano donde se ubica. Mención especial merecen las fotos sobre el periodo de la Guerra Civil española, cuando el edificio fue desalojado y sus sótanos fueron ocupados por la Junta Nacional de Defensa, presidida por el general Maja, durante gran parte de la contienda.

A lo largo de los últimos años, la Biblioteca Central ha ido incorporando los fondos de otras bibliotecas menores, como la Biblioteca de la Dirección General de Seguros y la Biblioteca de la Dirección General de Tributos. Merece destacarse, tanto por su nivel de especialización en doctrina económica y hacienda pública, como por la amplitud de sus fondos, la integración de la colección de la antigua Biblioteca de la Secretaría General Técnica.

Asimismo, desde 2019 las bibliotecas de la Intervención General de la Administración del Estado, de la Dirección General de Catastro y de la Dirección General de Tributos (de los fondos que ha conservado para uso exclusivo de su personal) se han integrado en el catálogo de la Biblioteca Central, conformando así un primer catálogo colectivo del Departamento. 


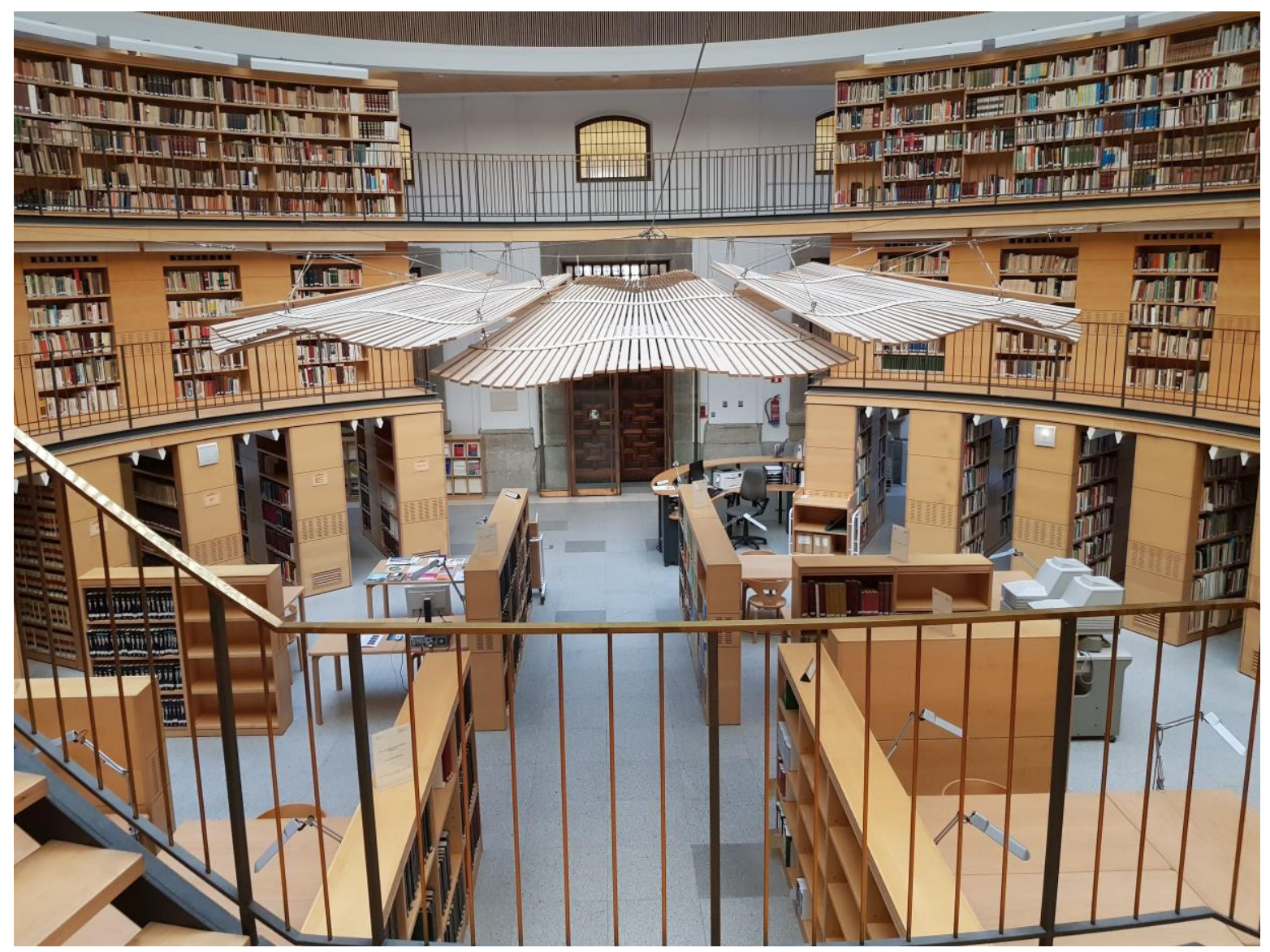

Figura2: Sala de lectura de la Biblioteca Central de Hacienda

Principales proyectos de la Biblioteca Central en 2021

Con objeto de dar mayor visibilidad a los fondos de la Biblioteca Central del Ministerio de Hacienda, durante 2021 se están llevando a cabo los proyectos siguientes:

- Fototeca: acceso a la colección de fotografías desde un espacio web accesible desde la página web del Ministerio de Hacienda y desde la intranet corporativa;

- Incorporación del catálogo a Worldcat de OCLC (en estudio);

- Incorporación del catálogo a la biblioteca digital Europeana (en estudio);

- Literaria: finalización de la catalogación de esta colección, formada por alrededor de 2.300 ejemplares de los siglos XIX y XX, destinada en su origen al préstamo domiciliario al personal del Ministerio, en vigor hasta 1979. Algunos ejemplares tienen un gran valor bibliográfico, bien por la calidad de su edición, por su rareza o por tratarse de primeras ediciones. 
Sobre la autora:

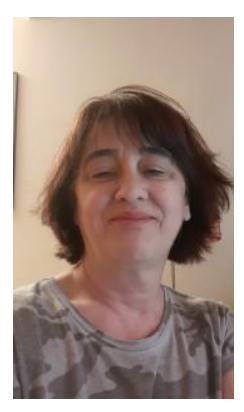

MARISA MARTÍNEZ SORO

Jefa de Servicio de la Biblioteca Central. Subdirección General de Información, Documentación y Publicaciones. Secretaría General Técnica.

Ministerio de Hacienda.

- Correo electrónico: marialuisa.martinez.soro@hacienda.gob.es

- Página web de la Biblioteca: https://www.hacienda.gob.es/esES/El\%20Ministerio/Paginas/Bibliotecas/Bibliotecas.aspx

- Catálogo de la Biblioteca: http://bibliotecacentral.minhafp.es/search*spi/ 